\title{
孙鸿烈谈第一次青藏高原综合科学考察
}

张莉, 张冬梅

\section{Honglie Sun: The First Tibetan Plateau Scientific Expedition and Research}

\section{Li Zhang \& Dongmei Zhang}

doi: 10.1360/TB-2019-0268

孙鸿烈, 中国科学院院士, 土壤地理学家和土地资源 学家, 长期从事我国自然资源综合考察与区域开发研究以 及青藏高原综合研究. 以“青藏高原的隆起及其对自然环 境和人类活动影响”和“青藏高原形成演化、环境变迁与生 态系统研究” 为中心问题, 领导开展多学科的综合研究, 20 世纪90年代领导建立了中国生态系统研究网络. 1987年当 选为第三世界科学院院士, 1991年当选为中国科学院院士. 曾任中国科学院副院长、国际科学联合会(ICSU)副主席、 中国环境与发展国际合作委员会(CCICED)中方首席专家、 国家气候变化专家委员会主任、国家环境咨询委员会副主 任、国家重点基础研究发展计划(973)项目专家顾问组资环 领域组长等职.

新中国成立前，对青藏高原地区的科学研究几乎处于 空白状态，只有极少数的外国探险家、传教士到过青藏高 原，收集了一些零星资料. 新中国成立后，党和政府极其 关心青藏高原的社会经济进步和科学事业的发展. 1951年 随着西藏和平解放, 政务院委派中国科学院组织随军工作 队进藏科学考察. 此后, 中国青藏高原综合科学考察研究 工作经历了不平凡的历程. 20 世纪70年代, 我国科学家对 青藏高原进行了第一次大规模综合科学考察，对青藏高原 的自然环境进行了全面调查, 获得了大量第一手资料, 填 补了青藏高原一些地区和学科研究的空白.

孙鸿烈院士参加了1973 1980年西藏自治区范围内的 综合考察，50多年来他几十次到青藏高原考察调研. 第二 次青藏高原综合科学考察研究(简称青藏科考)于2017年启 动，2018年9月5日在拉萨发布了首期成果. 为了进一步了 解青藏科考, 《科学通报》特邀请孙鸿烈院士回顾了第一 次青藏科考的历程. 以下为孙院士讲述的内容.

我是1961年从中国科学院沈阳林业土壤研究所调到在 北京的中国科学院综合考察委员会的. 当时中国科学院西 藏综合科学考察队组建不久, 队长冷冰同志是延安时期的 老干部，组织上安排我做考察队的学术秘书. 1960 1961年 考察队考察了甘南局部地区. 1962年因国家处于经济困难 时期，考察只能中断了.1962年，中国科学院又组织编写 了《综合科学考察十年规划》, 西藏考察是其中一个重要

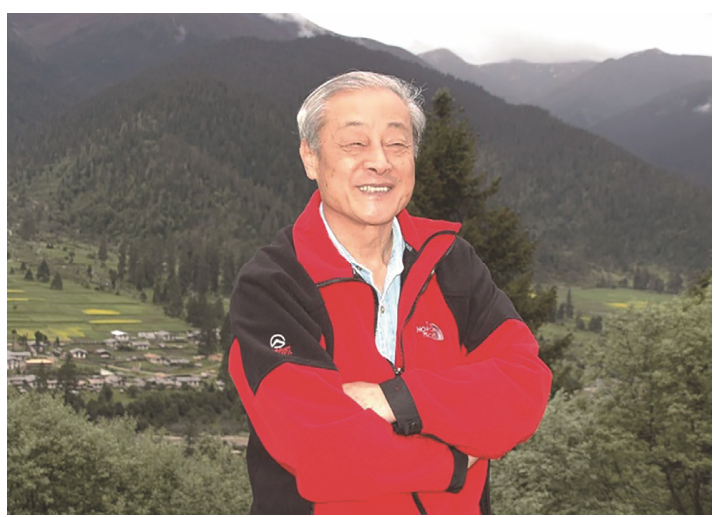

中国科学院院士 孙鸿烈

的内容. 遗憾的是, 由于种种原因, 这个规划未能实施.

20世纪60年代至70年代初，青藏高原也还有一些零星 的考察, 主要是与登山活动结合进行的. 如1959 1960年、 1966 1968 年两次对珠穆朗玛峰地区的登山科学考察, 1964年的希夏邦马峰登山科学考察等.

1972年，周恩来总理在一次谈话中强调了基础研究的 重要性. 在这个背景下, 中国科学院又组织参加过西藏考 察的人员研讨编制了《中国科学院青藏高原综合科学考察 规划》, 其中心任务是“阐明高原地质发展的历史及隆升的 原因，分析高原隆起后对自然环境和人类活动的影响，研 究自然条件与自然资源的特点及其利用改造的方向和途 径”，并于1973年成立中国科学院青藏高原综合科学考察 队，从此进人了青藏高原大规模综合科学考察的时期.

这一次青藏综合科学考察的思路很明确，就是对青藏 高原的自然环境做一次全面的调查, 把各种自然要素的资 料全面搜集起来. 因此, 考察队伍包括了地学、生物学、 农学等 50 多个专业，历时 4 年，前后有 770 多人参加. 每年 5 10月考察队开展野外工作，在野外分专业进行考察，有 时也有多个专业组联合行动.

1973 1976年，第一次青藏科考的区域从喜马拉雅山 脉到藏北无人区，从横断山区到阿里高原. 考察队员的足 迹遍及西藏自治区全境，历经艰难困苦，获得了大量第一 
手科学资料. 例如, 发现了蛇绿岩带、喜马拉雅地热带、 三趾马动物群化石、恐龙化石、盐类矿床和油气显示; 观 测到珠峰旗云、珠峰地面的强力加热作用和冰川风; 采集 并鉴定出 7 个植物新属、 300 多个植物新种, 以及 20 个昆虫 新属、400多个昆虫新种, 缺翅目昆虫的发现填补了一个 “目”的研究空白.

这一阶段, 经过 4 年的野外工作和近 4 年的室内总结, 到1980年陆续完成了《青藏高原科学考察丛书(西藏部分)》 共38部43册专著. 1978年全国科学大会上, 中国科学院青 藏高原综合科学考察队受到国务院嘉奖. 其后, “青藏高原 隆起及其对自然环境与人类活动影响的综合研究” 项目于 1986年获中国科学院科学技术进步特等奖, 1987年获国家 自然科学一等奖, 1989年获陈嘉庚地球科学奖.

1980 年以后的 10 多年间, 青藏高原综合科学考察队又 相继组织开展了横断山区、南迦巴瓦峰地区、喀喇昆仑一 昆仑山地区和可可西里地区的综合科学考察, 编写出版了 《横断山区科学考察丛书》《喀喇昆仑山与昆仑山科学考 察丛书》《可可西里地区科学考察丛书》等34部专著、两 本论文集, 以及 1 部《青藏高原地图集》.

第一次青藏科考的主要科学贡献在于阐明了高原隆起 是近百万年来地球历史上最重要的地质事件之一, 划分了 7个地层区和 5 条缝合带; 揭示了高原生物区系组成、起源 和演化的过程及规律; 查明了高原境内的自然条件的分布 规律, 划分了青藏高原的自然地带, 明确了各地带的资源 环境利用、保护方向与措施; 解析了高原气候变化对东亚 大气环流的影响.

第一次青藏科考还促成了青藏高原研究国际合作的局 面. 1980年在北京举办青藏高原国际科学讨论会, 邓小平 亲自会见与会中外代表. 这次国际会议为此后青藏高原国 际合作研究的蓬勃开展奠定了基础.

与现在的考察工作条件相比, 第一次青藏科考时的条 件和设备是非常简婳的. 比如说, 每次考察出发时, 我们 需要在成都集中, 然后乘坐 10 天左右的大卡车才能沿川藏 公路到达拉萨. 野外考察时吃饭也是个难题. 在营地时, 大家轮流做饭, 虽然厨艺不好, 而且没有新鲜蔬菜只有干 菜, 但毕竟还能吃上热饭. 可是到野外考察时中午就只能 吃压缩饼干了. 当时没有保温壸, 用水壸背的水到中午时 已是冰冷的了, 吃压缩饼干只能就唾沫下咽. 当时最大的 幸福是, 能经过藏族同胞的帐篷喝上一口热乎乎的酥油茶.

在那个时期, 国家对考察工作是倾全力支持的. 在凭
票证供应肉粮油的年代, 考察队可以到西藏军区购买肉罐 头、食用油和大米、白面，充分体现了军队对科考的支持. 有一次由于时间紧迫, 大批队员来不及及时进藏集结考 察, 中国科学院还特批包租了一架飞机, 将队员送到拉萨. 为了配合上海科教电影制片厂拍一个空中的鸟瞰镜头, 还 租了几天的飞机开展工作. 在每年的考察工作中, 车辆、 燃油、经费等基本上都得到了保证.

第一次青藏科考是从各个专业的角度分别对西藏的自 然资源和环境进行拉网式的调查. 考察队阶段性地进行专 业间的交流讨论, 使专业之间互相学到更多知识, 开阔了 各自的学术视野. 在野外工作期间, 大家就像一个大家庭 的成员一样朝夕相处, 在艰苦的野外环境中, 互相关心和 体贴.

可以说，第一次青藏科考开展前，我们对青藏高原的 资源环境的认识基本上处于空白状态. 所以, 第一次青藏 科考主要是填补空白. 在第一次青藏科考之后, 近二十多 年来又有不少对青藏高原的专题考察. 现在第二次青藏科 考启动了, 我国的青藏高原研究力量和研究积累都已经达 到了更高水平. 从第一次青藏科考启动到现在的近 50 年 内, 无论是青藏高原的生态环境还是青藏高原地区的社会 经济, 都发生了深刻的变化. 所以第二次青藏科考要针对 变化中出现的问题, 紧密联系科学前沿的理论问题和青藏 高原社会经济发展的应用问题. 特别要在以下几个方面发 力: 要从定性研究向定量研究发展, 实现定性与定量相结 合研究; 要从静态研究向动态研究转变, 揭示变化的过程 和机制; 单一学科研究与多学科交叉研究相结合, 实现综 合集成研究; 要从局部研究向区域研究与全球研究为主的 进击, 实现环境变化研究的区域联系.

回顾青藏高原科学考察研究的历程时, 老一辈科研人 员的科学精神、奉献精神被称为“青藏精神”. 我认为激励 一代代科技工作者奋发向上的“青藏精神”应该包括三个方 面：一是勇攀高峰、开拓创新的精神; 二是团结协作、互 相学习的精神; 三是不畏艰险、克服困难的精神.

对现在从事青藏高原研究的新一代年轻科研人员, 我 想说几句话: 第一, 要夯实基础, 当你们进人某个领域要 继续深人下去的时候, 会发现有很多相关学科的知识需要 补充; 第二, 要融人自然, 尽可能抓住机会到野外调查、观 测, 要深人到大自然, 掌握数据和规律; 第三, 要作为终 身的事业投人，从事青藏高原研究这项事业就要坚持不解 地钻研. 